\title{
Modification of Ni-Based Plasma Detonation Coatings by a Low-Energy DC E-Beam
}

\author{
D. Alontseva ${ }^{a, *}$, A. Krasavin ${ }^{a}$, A. Pogrebnjak ${ }^{b}$ And A. Russakova ${ }^{c}$ \\ ${ }^{a}$ East-Kazakhstan State Technical University, Protozanov 69, 070004, Ust-Kamenogorsk, Kazakhstan \\ ${ }^{b}$ Sumy State University, Rimsky Korsakov 2, 40007 Sumy, Ukraine \\ ${ }^{c}$ Eurasian National University, Munaitpasov 5, 010008 Astana, Kazakhstan
}

\begin{abstract}
The paper presents the study of Ni-based coatings deposited by plasma detonation onto a steel substrate after direct current low-energy electron beam irradiation and proposes explicit parameters of the electron beam for modification of coatings by irradiation. The choice of irradiation modes is based on the calculation of the temperature profile in the $\mathrm{Ni}$-Fe two-layer absorbents using numerical simulation methods. It was found that the exposure of coatings to irradiation according to the recommended modes leads to the evolution of the structural-phase state of coatings and substantial improvement of performance properties of modified surfaces. The wear resistance of modified surfaces increases 3 times, the microhardness increases on the average $25 \%$.
\end{abstract}

DOI: 10.12693/APhysPolA.123.867

PACS: 81.15.-z, 81.07.-b, 68.47.Gh

\section{Introduction}

The technology of plasma-detonation deposition of coatings on the surface of various materials and modification of their properties by irradiation has been intensively developing recently. The peculiarity of the plasma-detonation method is the formation of relatively thick coatings (thickness of $100-300 \mu \mathrm{m}$ ) in contrast to the physical vapour deposition (PVD) and chemical vapour deposition (CVD) methods, which form thin films on the substrate. The advantages of this method are that the coating deposition is carried out in air and does not require shielding gases and extra accessories to create a flow in the direction of the substrate. One of the main problems of plasma detonated thick coatings is their porosity, lack of homogeneity on account of poor agglomeration of powder particles, high roughness of surface and low adhesion to substrate. These result in insufficient corrosion and wear resistance of such coatings $[1,2]$. To improve the adhesion to the substrate and reduce the porosity of the coatings, they are exposed to re-melting by the plasma jet or electron irradiation; there is experience of industrial use of equipment processed according to the technology $[3,4]$.

The properties of irradiated materials are determined by their structural and phase composition, while the effect of irradiation - on phase stability is rather complicated. In the literature there has not been consensus yet on the effect of irradiation on the structure and properties of Ni-based coatings.

The aim of this work is to connect the evolution of the structural-phase state of plasma-detonation $\mathrm{Ni}$-based

*corresponding author; e-mail: dalontseva@mail.ru coatings as a result of their modification by a low energy direct current electron beam, which changes their performance characteristics.

\section{Material and methods of the experiment}

The protective coatings with a thickness of 150 to $300 \mu \mathrm{m}$ were formed using "Impulse-6" plasma-detonation facility on a substrate of quality carbon steel St 3 (Fe - base, C -0.25 wt $\%, \mathrm{Mn}-0.8 \mathrm{wt} \%, \mathrm{Si}-$ 0.37 wt $\%, P<0.045$ wt\%). They were deposited with the Ni-based powder alloys: PG-10N-01 $(\mathrm{Ni}$ - base material; $\mathrm{Cr}-14 \ldots 20 \mathrm{wt} \%, \mathrm{~B}-3.3 \mathrm{wt} \%, \mathrm{Si}-4.8 \mathrm{wt} \%$, Fe up to $7 \mathrm{wt} \%, \mathrm{C}-0.8 \mathrm{wt} \%)$ and PG-AN-33 (Nibase material; $\mathrm{Cr}-19-24 \mathrm{wt} \%$, Mo $-4 \mathrm{wt} \%, \mathrm{~B}-$ 2 wt $\%, \mathrm{Si}-2 \mathrm{wt} \%, \mathrm{~W}-1 \mathrm{wt} \%)$, GOST $28377-89$. The size fractions of the powder used for deposition varied from 56 to $100 \mu \mathrm{m}$. The steel samples with pre-blasted surface of $20 \times 30 \times 10 \mathrm{~mm}^{3}$ in size were used as the substrate material. The powder coatings were deposited in air with the following parameters of pulse-plasma treatment: the distance from the substrate to the nozzle $60 \mathrm{~mm}$; the travel speed of the sample $-360 \mathrm{~mm} / \mathrm{min}$; the powder consumption $-21.6 \mathrm{~g} / \mathrm{min}$, the pulse repetition frequency $-4 \mathrm{~Hz}$ (the detonation frequency). The electric current density in the plasma jet can vary from 1 to $7 \mathrm{~A} / \mathrm{cm}^{2}$; the average temperature of the plasma flow at the nozzle exit of the apparatus reaches the order of several thousands ${ }^{\circ} \mathrm{C}$; the average diameter of the jet on a sample is $25 \mathrm{~mm}$; the pulse duration is about $10 \mathrm{~ms}$. Erosive electrode - Mo.

The choice of the additional exposure modes is based on modeling temperature profiles in the coatings and the substrate during irradiation. We selected such modes of irradiation at which on the surface the Ni melting temperature is achieved, and on the border between the coating and the substrate the temperature is high enough to 
significantly accelerate the diffusion processes and to increase the width of the diffusion zone from the coating to the substrate, but not to lead to coating melting. The optimal modes were thought those that would lead to homogenization of the coating and improve its adhesion to the substrate due to the acceleration of diffusion processes during irradiation.

The irradiation of samples on the side of the surfaces according to the calculated modes was carried out in vacuum by an electron beam on the "U-212" generator with an accelerating voltage of $30 \mathrm{kV}$ in a continuous mode. The scan is saw-like; the beam travel speed in the horizontal direction is $360 \mathrm{~mm} / \mathrm{min}$; the diameter of the electron beam on the sample is $10 \mathrm{~mm}$; the current amperage is $20-30 \mathrm{~mA}$.

The studies of the surface structure and morphology were performed by scanning electron microscopy using JSM-6390LV ("JEOL", Japan) with the INCA energy dispersive analysis add-on unit (Oxford Instruments, UK).

The X-ray X'Pert PRO diffractometer (PANalytical, The Netherlands) was applied for the study of the coating structural and phase composition.

Microhardness tests of all the samples were carried out using a PMT-3 apparatus by angle laps with $1 \mathrm{~N}$ load on the indenter. The coating wear resistance tests were performed by the plane-cylinder triboconjunction scheme in the petroleum jelly environment on the SMTS-2 (Ukraine) installation at a load of $10 \mathrm{~N}$, sliding speed $-1.3 \mathrm{~m} / \mathrm{s}$ and the total number of revolutions - 1000. Cylinder material is VK8-alloy with $8 \%$ cobalt and $92 \%$ tungsten carbide (HRC 68-69). The volumetric wear of the material $\Delta V$ was measured every 500 revolutions. It was calculated according to the measurements of length and width of the area of wear from the contact of the cylinder with the test sample, and based on the data obtained with the profilometer - profiler (model 201 ), which recorded the surface topography in the coating perpendicular to the longitudinal axis of the friction track. Cylinder wear was determined by its weighing on an analytical balance (accuracy $\pm 0.1 \mathrm{mg}$ ) before and after the test.

\section{Results}

The model of the structure of $\mathrm{Ni}-\mathrm{Cr}$ based powder coatings deposited by plasma-detonation onto steel substrates was published in [5]. It was based on a series of experimental studies [5-8] of the structural-phase composition and properties of such coatings. The paper [8] points out to the reasons for the formation of zones with different structural and phase composition of the coatings, the location of these areas in a depth from the surface and their thickness. It is particularly important that there is a transition (diffusion) zone between the coating and the substrate, where the Ni-based $\gamma$-solid solution changes for the Fe-based solid solution with the bcc structure, and $\mathrm{Fe}_{7} \mathrm{Ni}_{3}$ or $\mathrm{FeNi}_{3}$ intermetallic phases evolve. The width of the diffusion zone is estimated on the average as $100 \mathrm{~mm}$ : $50 \mathrm{~mm}$ in the coating and $50 \mathrm{~mm}$ in the substrate (by processing the data on the distribution of microhardness across the depth from the surface, and according to the X-ray phase analysis data).

As a result of the coatings' modification by a DC electron beam, their microhardness increased on the average $25 \%$ (Fig. 1); the wear resistance increased up to twice; there was also observed a decrease in the volumetric wear of material $\Delta V$ compared with the same value for the initial coating material (Fig. 2, curves 2 and 3), especially at a large number of counterbody revolutions during the test. The wear resistance of modified surfaces increased 3 times in comparison with the substrate (Fig. 2, curves 1 and 3 ).
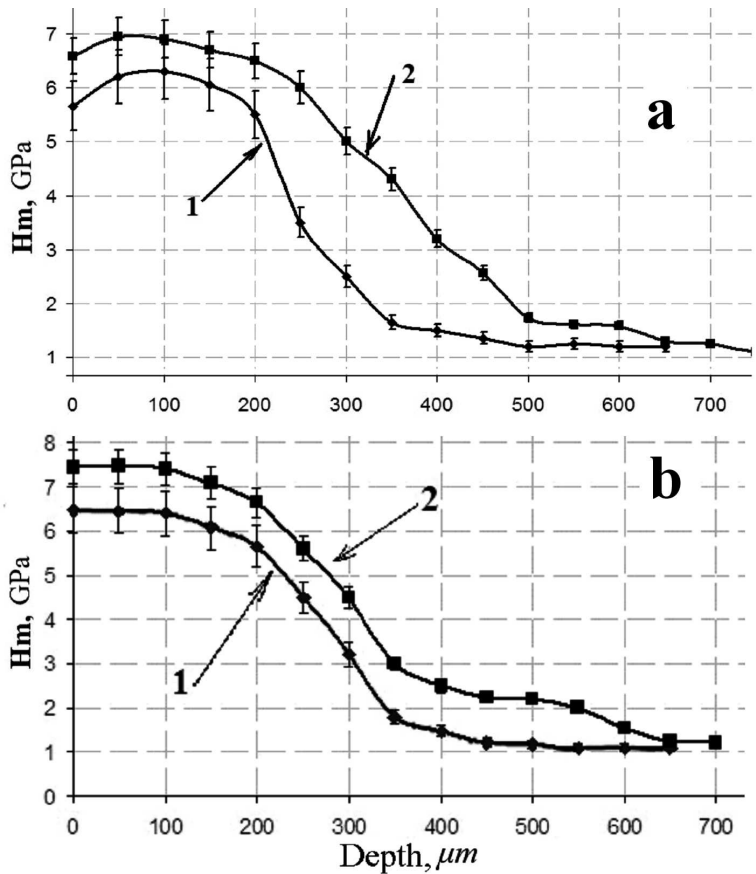

Fig. 1. The diagrams of the microhardness distribution across the depth of PG-19N-01 (a) and PG-AN-33 (b) coatings from the surface into the sample in the direction perpendicular to the surface $(1$ - lower curve) and after additional irradiation $(2-$ upper curves $)$.

The method of energy dispersive spectral analysis registers the penetration of $\mathrm{Ni}$ and $\mathrm{Si}$ from the irradiated coatings into the substrate. The modified form of the coating boundary with the substrate and the distribution map of the corresponding elements for the PG-10N-01 coating is shown in Fig. 3. The microstructure of the PG-AN-33 coating after irradiation is shown in Fig. 4. It features the fine-grained homogeneous microstructure with an average grain size of $2 \mu \mathrm{m}$ (Fig. 4).

The volume fraction of Ni-based solid solution in the coatings increased after irradiation on the average $5-9 \%$ according to the $\mathrm{X}$-ray phase analysis, the number of intermetallic phases, $\mathrm{Ni}$ and $\mathrm{Fe}$ compounds, increased (Table). 


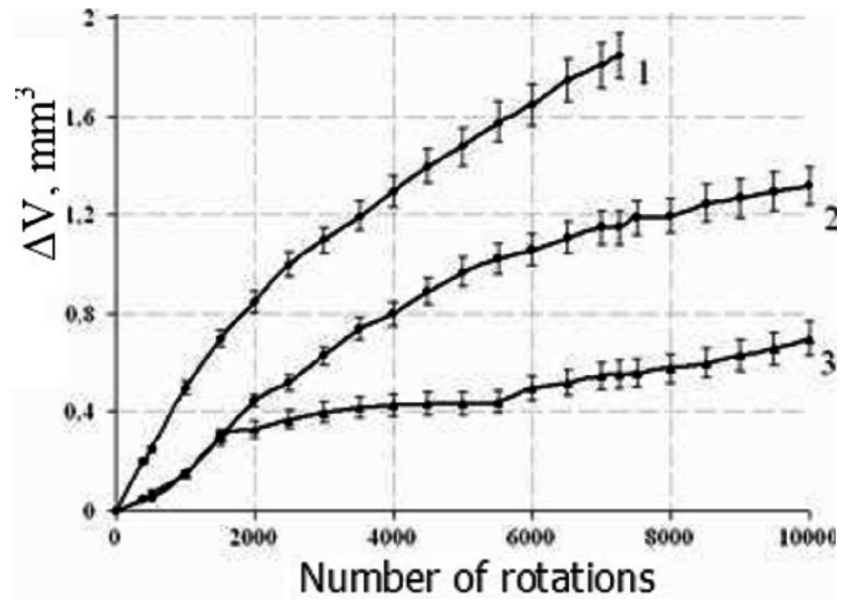

Fig. 2. Wear curves obtained on the substrate (1), the initial coatings (2) and after modification of the powder PG-10N-01 coating by irradiation (3).
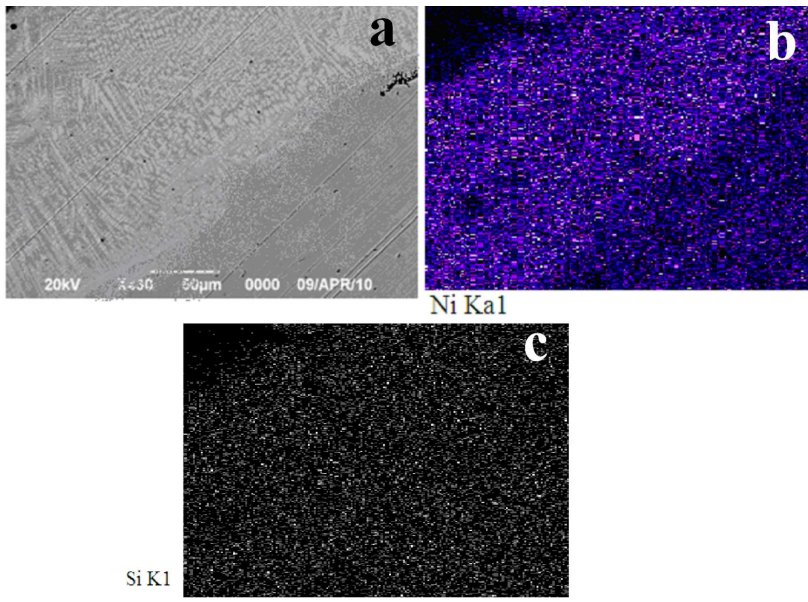

Fig. 3. The image of the cross-section of the PG-10N-01 coating on the steel substrate after electron irradiation (a) and the corresponding map of the $\mathrm{Ni}$ (b) and $\mathrm{Si}$ (c) distribution in the coating and the substrate.

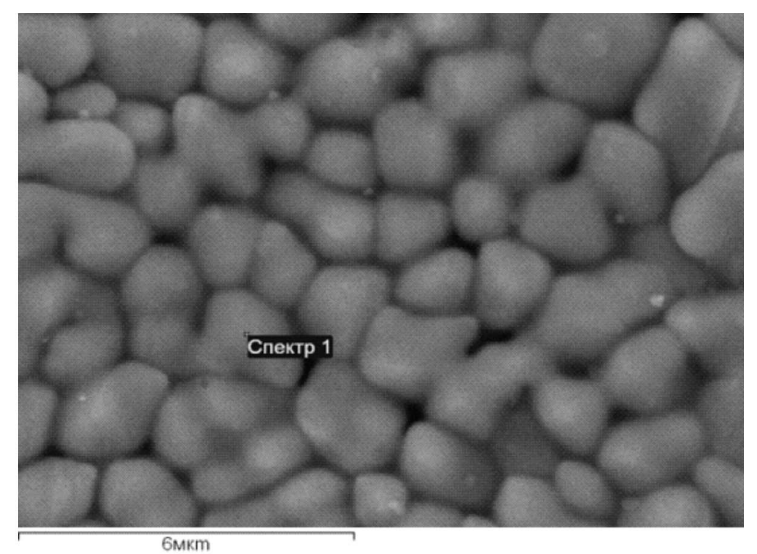

Fig. 4. The microstructure of the PG-AN-33 coating after irradiation.
TABLE

Phase composition of the plasma detonation coatings before and after modification.

\begin{tabular}{|c|c|c|}
\hline \multirow[t]{2}{*}{ material } & \multicolumn{2}{|c|}{$\begin{array}{l}\text { volume concentration [\%] || chemical formula || } \\
\text { crystal system || space group || } \\
\text { space group number || parameters }[\AA]\end{array}$} \\
\hline & Before irradiation & After irradiation \\
\hline \multirow{5}{*}{ PG-10N-01 } & $\begin{array}{l}65 \% \| \text { solid solution on } \\
\text { Ni-base }(\gamma \text {-phase) } \| \\
\text { cubic }\|F m-3 m\| \\
(225) \| a=3.59 \ldots 3.60 \\
\end{array}$ & $\begin{array}{l}74 \% \| \text { solid solution on } \\
\text { Ni-base }(\gamma \text {-phase }) \| \\
\text { cubic }\|F m-3 m\| \\
(225) \| a=3.5(8)\end{array}$ \\
\hline & $\begin{array}{l}15 \%\left\|\mathrm{CrNi}_{3}\right\| \text { cubic } \| \\
F m-3 m\|(225)\| \\
a=3.5520\end{array}$ & $\begin{array}{l}17 \%\left\|\mathrm{CrNi}_{3}\right\| \text { cubic } \| \\
F m-3 m \| \\
(225) \| a=3.552\end{array}$ \\
\hline & $\begin{array}{l}10 \%\left\|\mathrm{FeO} \mathrm{Cr}_{2} \mathrm{O}_{3}\right\| \\
\text { cubic }\|F d-3 m\| \\
(227) \| a=8.3440\end{array}$ & $\begin{array}{l}3 \%\left\|\mathrm{Fe} \mathrm{Ni}_{3}\right\| \text { cubic } \| \\
F m-3 m\|(225)\| \\
a=3.5556\end{array}$ \\
\hline & $\begin{array}{l}10 \%\|\mathrm{NiO}\| \text { cubic } \| \\
F m-3 m\|225\| a=4.2\end{array}$ & $\begin{array}{l}3 \%\left\|\mathrm{Fe}_{7} \mathrm{Ni}_{3}\right\| \text { cubic } \| \\
\operatorname{Im}-3 m\|(229)\| \\
a=2.861\end{array}$ \\
\hline & $\begin{array}{l}3 \%\left\|\mathrm{Fe}_{7} \mathrm{Ni}_{3}\right\| \mathrm{cubic} \| \\
\operatorname{Im}-3 m\|(229)\| \\
a=2.861\end{array}$ & \\
\hline \multirow{5}{*}{ PG-AN-33 } & $\begin{array}{l}80 \% \| \text { solid solution on } \\
\text { Ni-base }(\gamma \text {-phase }) \| \\
F m-3 m\|(225)\| \\
a=3.5960\end{array}$ & $\begin{array}{l}85 \% \| \text { solid solution on } \\
\text { Ni-base }(\gamma \text {-phase }) \| \\
F m-3 m\|(225)\| \\
a=3.5350\end{array}$ \\
\hline & $\begin{array}{l}10 \%\left\|\mathrm{CrNi}_{3}\right\| \text { cubic } \| \\
F m-3 m\|(225)\| \\
a=3.5520\end{array}$ & $\begin{array}{l}6 \% \| \text { solid solution on } \\
\text { Fe-base } \| \text { cubic } \| \\
\text { Im-3m }\|(229)\| \\
a=2.8664\end{array}$ \\
\hline & $\begin{array}{l}10 \%\left\|\mathrm{FeO} \mathrm{Cr}_{2} \mathrm{O}_{3}\right\| \\
\text { cubic }\|F d-3 m\| \\
(227) \| a=8.3440\end{array}$ & $\begin{array}{l}7 \%\left\|\mathrm{CrNi}_{3}\right\| \text { cubic } \| \\
F m-3 m\|(225)\| \\
a=3.5520\end{array}$ \\
\hline & & $\begin{array}{l}1 \%\left\|\mathrm{FeNi}_{3}\right\| \text { cubic } \| \\
F m-3 m\|(225)\| \\
a=3.5556\end{array}$ \\
\hline & & $\begin{array}{l}1 \%\left\|\mathrm{Mo}_{2} \mathrm{C}\right\| \text { hexagonal } \\
\|P 63 / m m c\|(194) \| \\
a=3.0029, b=3.0029, \\
c=4.7290\end{array}$ \\
\hline
\end{tabular}

\section{Results and discussion}

The improvement of the operational properties of the coating is firstly due to the achieved increase of the width of the diffusion zone between the coating and the substrate. The penetration of $\mathrm{Ni}$ and $\mathrm{Si}$ from the irradiated coating into the substrate is confirmed experimentally (Fig. 3). The diagrams of microhardness distribution with depth (Fig. 1) show the increase in the microhardness values in the transition layer between the coating and the substrate, which also confirms the increase in the width of the diffusion zone. The $\mathrm{Ni}$ and $\mathrm{Si}$ depth of penetration in the substrate achieves more than $100 \mu \mathrm{m}$ (Fig. 3). Secondly, the microhardness of the coating increases on account of the increase of the total volume fraction of intermetallic phases in the coatings after irradiation (Table). Thirdly, the formation of a rather homogeneous fine-grained structure in the irradiated coat- 
ings (Fig. 4) indicates the homogenization of the coating structure. The increase in wear resistance after the DC e-beam treatment (Fig. 2, curve 3) indicates improvement in the coating adhesion to the substrate. Thus, there is fair conformity between the experimental results with the acceleration of diffusion processes expected on the basis of a model experiment.

We expected development of radiation-enhanced diffusion in the absorbing materials during irradiation; but without experimental measurement of diffusion coefficients we are unable to predetermine the contribution of one or another factor to the acceleration of mass transfer except that by circumstantial evidence. The source [9], where the theoretical and experimental information related to the issue of radiation-induced structural phase changes in materials is summed up, indicates that electron irradiation usually leads to migration of vacancies in the irradiated material, which may, in turn, lead to redistribution of dissolute atoms. It [9] also emphasizes that in the austenitic $\mathrm{Fe}-\mathrm{Cr}-\mathrm{Ni}$ alloys $\mathrm{Ni}$ interacts with vacancies to the smallest extent, so it enriches the areas around the effluents; chrome, a fast diffusant, migrates towards the vacancy flow (i.e. in the direction opposite to the effluents); silicon, which is strongly connected with the interstitial atoms, moves to the effluents along with them. The TEM investigation ([9], p. 150) has pointed out that the effluents in point defects are pores, surfaces, dislocation lines and dislocation loops as well as grain boundaries. We believe that the $\mathrm{Ni}$ and $\mathrm{Si}$ distribution in the Fe-based substrate and the coating after exposure, observed in Fig. 3, is consistent with the described phenomenon of $\mathrm{Ni}$ and $\mathrm{Si}$ migration to the effluents, which are plenty in the boundary zone between the coating and the substrate. Thus, the experimentally observed redistribution of the coating elements into the substrate due to the electron irradiation is consistent with the observed and theoretically described by other authors phenomenon of radiation-enhanced diffusion.

\section{Conclusions}

The irradiation of coatings by a DC e-beam according to the recommended modes leads to the evolution of the structural-phase state of coatings: an increase in the size of the diffusion zone between the coating and the substrate, an increase in the volume fraction of hardening intermetallic phases, the formation of a sufficiently homogeneous fine-grained structure in the irradiated coatings and, consequently, a significant increase of hardness and wear resistance of modified coatings. The observed redistribution of the elements of the coating into the substrate indicates the acceleration of diffusion processes during irradiation (presumably of the radiation-enhanced diffusion).

\section{References}

[1] P. Misaelides, A. Hatzidimitou, F. Noli, A.D. Pogrebnjak, Y.N. Tyurin, S. Kosionidis, Surf. Coat. Technol. 180-181, 290 (2004).

[2] E. Celik, I. Ozdemir, E. Avci, Y. Tsunekawa, Surf. Coat. Technol. 193, 297 (2005).

[3] K.K. Kadyrzhanov, F.F. Komarov, A.D. Pogrebnyak, V.S. Russakov, T.E. Turkebaev, Ion-Beam and IonPlasma Modification of Materials, MGU, Moscow 2005.

[4] Yu.F. Ivanov, E.V. Naidenkin, Russ. Phys. J. 52, 1030 (2009).

[5] D.L. Alontseva, in: Abstract Book of the Fourth Int. Conf. Deformation \& Fracture of Materials and Nanomaterials, Moscow, 2011, p. 446.

[6] D.L. Alontseva, S.N. Bratushka, A.A. Borysenko, N.V. Prokhorencova, V.T. Shablya, Metallofiz. Nov. Teknol. 33, 721 (2011) (in Russian).

[7] D. Alontseva, Przeglad Elektrotechniczny 86, 42 (2010) (in Polish).

[8] A.D. Pogrebnjak, Sh.M. Ruzimov, D.L. Alontseva, Vacuum 81, 1243 (2007).

[9] F.V. Nolfi, Phase Transformation during Irradiation, Metallurgiya, Chelyabinsk 1989, p. 311. 